\title{
On reification: a reinterpretation of designed and emergent practice
}

\author{
Chris Tompsett and Graham Alsop \\ Kingston University \\ email:c.p.tompsett@kingston.ac.uk
}

This paper is a response to the article: 'Examining the five-stage e-moderating model: designed and emergent practice in the learning technology profession', published in ALT-J 11 (1). Whilst we agree with the concerns of the authors on the problems of commodification and the increasing control of learning technology from a financial or predominantly management perspective, we wish to offer a reinterpretation of the research by taking a stricter analysis of the events described by the authors.

\section{Models of best practice}

As we understand, the research follows the design and evaluation of a training course on running e-courses. The design of the course took into account various 'models' that either as embodied in software or as discussed in the literature can be considered to represent current knowledge or best practice in order to provide academic legitimacy to the design. The principal models would seem to be: an MLE/VLE technical framework (aligned to a corporate world), the learning paradigm of communities of practice (Wenger, 1998) and the e-moderating five-stage model (from Salmon, 2000). Anecdotal evidence from the evaluation suggests that the participants found the course constraining. This suggested that these 'models' may be useful but are dangerous if such 'reifications' stultify development in 'communities of practice'.

These set models cover a number of epistemological frameworks. The corporate world is framed within the politics and economics of delivery in higher education, the five-stage model within action research (Salmon, 2000: 24-5) and 'communities of practice' within situated learning (Lave and Wenger, 1991). The evaluation of the course remains anecdotal. Our view is that a single framework removes many inconsistencies and offers a 
Chris Tompsett and Grahom Alsop On reification: a reinterpretation of designed and emergent practice

more positive future for the community of learning technologists. The framework that we choose is 'situated learning'. From this point onwards it is critical that all terminology is applied within this framework.

\section{A single framework}

The concept of 'community of practice' (Wenger, 1998: 6-7, 47-52, 72-84) is the starting point in Wenger's understanding of society, with meaning (revealed through participative practice, ibid.: 51-65); learning and identity are derivative concepts. Reification (ibid.: 55, 57-62) refers to the collection of processes or devices through which we communicate meaning with others in the community: "we project ourselves onto the world and, not having to recognize ourselves in those projections, we attribute to those meanings an independent existence' (ibid.: 58). Organizations and education are only considered in the last two chapters.

A strict interpretation for 'community of practice' and 'reification' are central to our analysis. Several communities are easily identified from the article written by Lisewski and Joyce: the managers of the institution, the providers of the software, the researchers as learning technologists, the researchers running the course, the participants on the course and other academics. However, a community is not automatically 'a community of practice'. A 'community of practice' requires mutual engagement, shared repertoire and common enterprise (ibid.: 73). Within this definition there is sufficient evidence that these communities represent distinct 'communities of practice' (though individuals may belong to more than one such community). Let us presume, for the sake of argument, that the community of learning technologists can be considered as one 'community of practice' and address the concept of reification.

When a 'community of practice' reifies some aspect of a practice, for example a software or a design model, then it is not possible to separate the reified model (as published) from the way in which it is used in practice - since 'at the level of meaning, the process and the product are not distinct' (ibid.: 60). The meaning of a five-stage model, for example, is represented by its actual use in the community. The authors' research is one part of that meaning. Reification only occurs when the use of a model becomes an equal part of practice, 'participation and reification cannot be considered in isolation; they come as a pair' (ibid.: 62). From Wenger's perspective, the five stages have not yet been reified in the community of practice of learning technologists.

Such an argument can also be applied to the VLE/MLE system used. In this case a further distinction can be made. The VLE/MLE represents a model that would have different meanings, through practice, in each community of practice. In Wenger's model the technical system is common and acts as a boundary object (ibid.: 106-8). The meaning for each community of practice will be different and can act as a point of conflict or coordination (ibid.: 107). Even if the VLE/MLE model is commodified within the community of management, it is not the same as a 'reification' in that community, let alone the same reification in other communities of practice.

For Wenger the design of learning is complicated since learning derives from practice (ibid.: 214) and, by implication, negotiation. In most educational institutions mutuality and learning through practice are difficult to achieve (ibid.: 264-5). The aim is that the 
design of education does not prevent learning through practice (ibid.: 229, 267). In this case, the learners may have been provided with experience of these models, but the models have become more critical than the practice of e-moderation. To present a fixed structure, whether the structure should support negotiated meaning or not, is to force a separation between the planned (teaching) and the emergent (learning) (ibid.: 266-7). For Wenger, participation in learning must include both mutuality and negotiation.

\section{A reinterpretation}

In concluding, we would not, from Wenger's perspective, consider the models as described by the authors as stultifying. The models used cannot be separated from their use in practice and there is little evidence that practice is wide enough to establish reifications of how they should be used. It is only through practice that such objects could ever become reified (and only then stultified). The community of education technology practitioners. reifies them itself and not the institution to which it belongs:

One can attempt to institutionalize a community of practice, but the community of practice itself will slip through the cracks and remain distinct from its institutionalization. (ibid.: 229)

It would be possible to provide more detailed analysis of other issues but this would require more time and space. One final comment is perhaps required as to the choice of Wenger's model as a framework for interpretation of the original article. We selected Wenger's approach as it allows us to describe the wide range of issues that were originally described, although activity theory (Nardi, 2001) or action research (McNiff, 1992) would also be possible and both could produce different views. What remains critical is the application of a single framework from the design of the activity through to evaluation and analysis.

Finally, we return to the assumption above that the community of learning technologists is a 'community of practice'. The repertoire, points of mutual engagement and shared enterprise appear confused if we allow any particular technology to determine the repertoire. No consistent practice is likely to evolve. If we exclude particular technology, but include within the repertoire the methods for understanding learning and the impact of technology on the learning process we may continue to make progress.

\section{References}

Lave, J. and Wenger, E. (1991), Situated Learning Legitimate Peripheral Participation, Cambridge: Cambridge University Press.

McNiff, J. (1992), Action Research: Principles and Practice, London: Routledge.

Nardi, B. A. (ed.) (1996), Context and Consciousness Activity Theory and Computer Interaction, Cambridge, MA: MIT Press.

Salmon, G. (2000), E-Moderating the Key to Teaching and Learning Online, London: Kogan Page.

Wenger, E. (1998), Communities of Practice: Learning, Meaning and Identity, Cambridge: Cambridge University Press. 